\title{
The role of surface charge in the desolvation process of gelatin: implications in nanoparticle synthesis and modulation of drug release
}

This article was published in the following Dove Press journal:

International Journal of Nanomedicine

24 January 2017

Number of times this article has been viewed

\author{
Saad MAhsan \\ Chintalagiri Mohan Rao \\ Centre for Cellular and Molecular \\ Biology, Council of Scientific and \\ Industrial Research, Hyderabad, \\ Telangana, India
}

Correspondence: Chintalagiri Mohan Rao Centre for Cellular and Molecular Biology, Council of Scientific and Industrial Research, Hyderabad 500007, Telangana, India

$\mathrm{Tel}+9|4027| 9563 \mid$

Fax +914027195633

Email mohan@ccmb.res.in

\begin{abstract}
The process of moving hydrophobic amino acids into the core of a protein by desolvation is important in protein folding. However, a rapid and forced desolvation can lead to precipitation of proteins. Desolvation of proteins under controlled conditions generates nanoparticles - homogeneous aggregates with a narrow size distribution. The protein nanoparticles, under physiological conditions, undergo surface erosion due to the action of proteases, releasing the entrapped drug/gene. The packing density of protein nanoparticles significantly influences the release kinetics. We have investigated the desolvation process of gelatin, exploring the role of $\mathrm{pH}$ and desolvating agent in nanoparticle synthesis. Our results show that the desolvation process, initiated by the addition of acetone, follows distinct pathways for gelatin incubated at different $\mathrm{pH}$ values and results in the generation of nanoparticles with varying matrix densities. The nanoparticles synthesized with varying matrix densities show variations in drug loading and protease-dependent extra- and intracellular drug release. These results will be useful in fine-tuning the synthesis of nanoparticles with desirable drug release profiles.
\end{abstract}

Keywords: protein desolvation, nanoparticle assembly, gelatin nanoparticle synthesis, protease susceptibility, intracellular drug release

\section{Introduction}

Proteins are excellent materials for nanoparticle-based drug/gene delivery applications. ${ }^{1}$ They are biocompatible, metabolizable and amenable to surface modifications and ligand attachments for targeted delivery. ${ }^{2-4}$ Desolvation is one of the common methods reported for protein nanoparticle synthesis, owing to its reproducibility and ease of preparation. ${ }^{5,6}$ The process of removing/replacing solvating water molecules, by a non-solvent, from the hydration shell of a macromolecule is called desolvation. ${ }^{7}$ Under physiological conditions, proteins tend to bury their nonpolar residues in the core to minimize solvent exposure along with increasing the surface exposure of polar residues. ${ }^{8}$ This process not only contributes in protein folding but also increases the solubility of proteins in water. ${ }^{7,9}$ When the critical balance between electrostatic and hydrophobic interactions is disturbed, proteins tend to undergo phase separation and precipitate. ${ }^{10} \mathrm{~A}$ rapid and forced desolvation of proteins thus leads to precipitation. However, desolvation under controlled experimental conditions generates homogeneous aggregates with a narrow size distribution which may be subsequently stabilized by chemical cross-linking. ${ }^{11-13}$

Several soluble and insoluble proteins such as elastin, ${ }^{14}$ albumin, ${ }^{15}$ gelatin, ${ }^{5}$ legumin, ${ }^{16}$ zein, ${ }^{17}$ soya ${ }^{18}$ and casein ${ }^{19}$ are being used to make protein nanoparticles. Gelatin and albumin have been extensively used for nanoparticle preparation by the 
desolvation method. ${ }^{20}$ Gelatin is a collagen derivative, and its properties are largely determined by the collagen source. A common characteristic feature of collagens, and hence gelatin, is the triple helical conformation, ${ }^{21}$ which is attributed to the conserved amino acid sequence repeat of Gly-X-Y, where glycine constitutes $33 \%$ of the sequence. The other major constituents are hydroxyproline, proline (combined $21 \%$ ) and alanine (10\%). ${ }^{22}$ The unique amino acid composition of gelatin is responsible for its unusual hydrogen bonding properties and hence a high water retention capacity. ${ }^{23,24}$

The preparation of nanoparticles by the desolvation method has been well studied and documented. ${ }^{25,26}$ The effect of various reaction parameters such as temperature and $\mathrm{pH}$ on nanoparticle size has been investigated..$^{27}$ Proteaseinduced degradation of the nanoparticle matrix is considered the major mechanism of drug release, this could be either by bulk degradation or by surface erosion. ${ }^{26,28}$ Considering the surface area to volume ratio of nanoparticles, size is an important factor in determining the degradation rates by surface erosion. Yet another, rather less explored parameter important in determining the rate of drug release, is the matrix density. The desolvation process, under appropriate conditions, provides an opportunity to synthesize nanoparticles with varying matrix densities and hence a differential susceptibility toward proteases.

In the current study, we have investigated the mechanistic details of the desolvation process of gelatin, exploring the role of $\mathrm{pH}$ and desolvating agent in nanoparticle synthesis. Our results provide interesting insights into the mechanistic details of gelatin nanoparticle (GNP) assembly. We were able to produce nanoparticles with different matrix densities which show variations in their degradation kinetics, drug loading and protease-based extra- and intracellular drug release.

The results provided in the current study will be helpful in designing protein nanoparticles with the desired susceptibility toward proteases and hence tunable drug release profiles.

\section{Materials and methods Materials}

Gelatin, from bovine skin, lime cured (type B), with bloom strength of 225, Nile Red (9-diethylamino-5H-benzo[ $\alpha]$ phenoxazine-5-one) and fluorescein were obtained from Sigma-Aldrich (St Louis, MO, USA). Glutaraldehyde (25\% aqueous solution) was obtained from Calbiochem. Acetone (high-performance liquid chromatography [HPLC] grade) was obtained from Spectrochem (Mumbai, India). Pronase was obtained from Roche. LysoTracker ${ }^{\circledR}$ Red DND-99 was obtained from Thermo Fisher Scientific
(Waltham, MA, USA). Vectashield antifade mounting medium with 4',6-diamidino-2-phenylindole (DAPI) was obtained from Vector Laboratories (Burlingame, CA, USA). All chemicals were of analytical reagent grade quality.

\section{Zeta potential measurements}

The zeta potential of gelatin in deionized water $\left(10 \mathrm{mg} \mathrm{mL}^{-1}\right)$ with $\mathrm{pH}$ ranging from 1.5 to 7.5 was recorded using a "Nanopartica" nanoparticle analyzer system (Horiba Scientific, Kyoto, Japan) at $25^{\circ} \mathrm{C}$.

\section{Probing hydrophobic surfaces of gelatin using Nile Red fluorescence}

Nile Red $(50 \mu \mathrm{M})$ was added to the sample of gelatin $\left(0.5 \mathrm{mg} \mathrm{mL}^{-1}\right)$, in water of $\mathrm{pH}$ ranging from 2.5 to 5.5 . Fluorescence spectra were recorded from 550 to $800 \mathrm{~nm}$ using a Hitachi F-7000 fluorescence spectrophotometer (Hitachi High Technologies America Inc, Schaumburg, IL, USA) with the excitation wavelength set at $540 \mathrm{~nm}$. The excitation and emission band passes were set at $5 \mathrm{~nm}$.

\section{Nanoparticle synthesis}

The double desolvation method proposed by Coester et $\mathrm{al}^{5}$ was used for nanoparticle synthesis. Briefly, a $5 \%(\mathrm{w} / \mathrm{v})$ gelatin solution was obtained by dissolving $2.5 \mathrm{~g}$ of gelatin type B (Bloom 225) in deionized water $(50 \mathrm{~mL})$ under gentle heating $\left(50^{\circ} \mathrm{C}\right)$. The first desolvation step was carried out by a rapid addition of $50 \mathrm{~mL}$ of acetone to the gelatin solution. The supernatant containing low molecular weight gelatin fraction was discarded, and the precipitated high molecular weight gelatin fraction was resolubilized in deionized water and lyophilized. The lyophilized high molecular weight gelatin $(0.1 \mathrm{~g})$ was then dissolved in $10 \mathrm{~mL}$ of deionized water under gentle heating $\left(50^{\circ} \mathrm{C}\right)$ to obtain a $1 \%$ gelatin solution. The solution was filtered with a $0.22 \mu \mathrm{m}$ filter, and the $\mathrm{pH}$ was adjusted to the desired value by the addition of $0.1 \mathrm{~N} \mathrm{HCl}$ or $0.1 \mathrm{~N} \mathrm{NaOH}$. Nanoparticle synthesis was then initiated by the dropwise addition of acetone under continuous stirring ( $500 \mathrm{rpm})$. After the addition of the desired amount of acetone, $20 \mu \mathrm{L}$ of glutaraldehyde ( $25 \%$ ) diluted in $1 \mathrm{~mL}$ of acetone was added to the reaction mixture for nanoparticle cross-linking. The solution was further stirred for 12 hours (h). The nanoparticles were subsequently purified by a three-step centrifugation $(48,000 \times g$ for $10 \mathrm{~min})$ and redispersion in acetone/ water (30/70 mixture). The purified nanoparticles were stored as dispersion in deionized water at $4^{\circ} \mathrm{C}-8^{\circ} \mathrm{C}$ or lyophilized. The nanoparticles were analyzed for their size and polydispersity in a "Nanopartica" nanoparticle analyzer system 
(Horiba Scientific) equipped with a diode-pumped solid state (DPSS) laser of wavelength $532 \mathrm{~nm}$ and a temperature controller unit.

For studying the effect of $\mathrm{pH}$ on nanoparticle size, gelatin (10 $\mathrm{mg} \mathrm{mL}^{-1}$ ) was incubated at the desired $\mathrm{pH}$. The amount of acetone added to obtain the nanoparticles was, however, varied. All other parameters were kept constant.

For studying the effect of acetone concentration on nanoparticle size, gelatin type B $\left(10 \mathrm{mg} \mathrm{mL}^{-1}\right)$ was incubated at the desired $\mathrm{pH}$, while all other parameters were kept constant. Desolvation was initiated by the addition of acetone. During the process of acetone addition, $1 \mathrm{~mL}$ of sample was withdrawn, treated with $2 \mu \mathrm{L}$ of glutaraldehyde (25\%) and kept on a rotator for $12 \mathrm{~h}$. After stirring for $12 \mathrm{~h}$, the nanoparticles were washed and analyzed for their size as described earlier.

The high matrix density-GNPs (HMD-GNPs) and the low matrix density-GNPs (LMD-GNPs) were synthesized by incubating gelatin type $\mathrm{B}\left(10 \mathrm{mg} \mathrm{mL}^{-1}\right)$ at $\mathrm{pH} 4$ and 3.25 , respectively. The amount of acetone added to obtain nanoparticles was $\sim 57 \%$ for HMD-GNPs and 73\% for LMD-GNPs. All other parameters were kept constant, and the procedure described earlier was followed.

\section{Loading of fluorescein into GNPs}

GNPs were soaked in an aqueous fluorescein solution (fluorescein to GNP ratio, 1:10) at room temperature. After $24 \mathrm{~h}$, the nanoparticles were purified by dialysis (molecular weight cutoff [MWCO], 8-12 K; Serva Electrophoresis GmbH, Heidelberg, Germany) against deionized water overnight to remove the unloaded free fluorescein. To determine the loading efficiency (LE) of fluorescein, the nanoparticles were digested with $10 \mu \mathrm{g} \mathrm{mL}^{-1}$ pronase at $37^{\circ} \mathrm{C}$ and the concentration of fluorescein in the solution was measured by monitoring the absorbance at $492 \mathrm{~nm}$ using a Perkin Elmer (Waltham, MA) spectrophotometer. A linear standard curve, obtained by fitting the absorbance and concentration of a series of fluorescein dilutions, was used to determine the concentration of fluorescein in the pronase digested nanoparticle samples. The LE was calculated by the formula:

Loading effeciency (\%)

$$
=\frac{\text { Amount of fluorescein in nanoparticles }}{\text { Initial amount of fluorescein used }} * 100
$$

\section{Degradation kinetics of GNPs}

GNPs $\left(2.5 \mathrm{mg} \mathrm{mL}^{-1}\right)$ were resuspended in phosphate-buffered saline (PBS), and pronase was added to a final concentration of $10 \mu \mathrm{g} \mathrm{mL}{ }^{-1}$. Nanoparticle scattering was monitored at
$365 \mathrm{~nm}$ with the temperature set at $37^{\circ} \mathrm{C}$ using a Hitachi F-7000 fluorescence spectrophotometer equipped with a temperature controller unit.

\section{Fluorescein release rates from GNPs}

Fluorescein-loaded GNPs were resuspended in PBS with varying concentrations of pronase $\left(0 \mathrm{mg} \mathrm{mL}^{-1}, 0.01 \mathrm{mg} \mathrm{mL}^{-1}\right.$ and $0.1 \mathrm{mg} \mathrm{mL}^{-1}$ ) and incubated at $37^{\circ} \mathrm{C}$. The GNPs were centrifuged at specific time intervals, and the supernatant was collected for fluorescein estimation. The pellet was resuspended in PBS with the desired amount of pronase and incubated further.

\section{Intracellular stability of fluorescein- loaded GNPs}

Mouse monocyte/macrophage cells (RAW 264.7) were cultured in Dulbecco's Modified Eagle's Medium (DMEM) supplemented with 10\% fetal bovine serum (FBS) and antibiotics $\left(5 \mu \mathrm{g} \mathrm{mL}^{-1}\right.$ penicillin and $6 \mu \mathrm{g} \mathrm{mL}^{-1}$ streptomycin) at $37^{\circ} \mathrm{C}$ under $95 \%$ humidity and $5 \% \mathrm{CO}_{2}$. Cells seeded on coverslips were incubated with $200 \mu \mathrm{g} \mathrm{mL}^{-1}$ of fluoresceinloaded GNPs for $4 \mathrm{~h}$. The cells were washed and cultured in complete DMEM for different time intervals. At indicated time points ( $0 \mathrm{~h}, 8 \mathrm{~h}, 16 \mathrm{~h}$ and $24 \mathrm{~h})$, cells were washed, stained with LysoTracker as per the manufacturer's instructions and fixed with $4 \%$ formaldehyde. Cells were counterstained with DAPI, and images were acquired using a $63 \times$ objective lens on a Leica confocal microscope (TCS-SP8; Leica Microsystems, Wetzlar, Germany). Images were analyzed by Leica Application Suite AF software provided by the company.

\section{Results and discussion Nanoparticle synthesis by the desolvation method}

The desolvation protocol developed by Marty et $\mathrm{al}^{6}$ and modified by Coester et $\mathrm{al}^{5}$ has been extensively used for the synthesis of protein-based nanoparticles. The process adopted in this study is described in Scheme 1, which includes adjusting the $\mathrm{pH}$ of the solution to impart a net charge on the protein molecules. Nanoparticle synthesis is then initiated by the addition of a desolvating agent. The size of the nanoparticles may be regulated by manipulating the reaction conditions. Previous studies have shown the size modulation by varying the amount and rate of addition of desolvating agent (acetone), $\mathrm{pH}$, temperature, concentration of the protein, and the amount of the cross-linking agent. ${ }^{27,29,30}$ The size of the nanoparticles, which determines the surface 


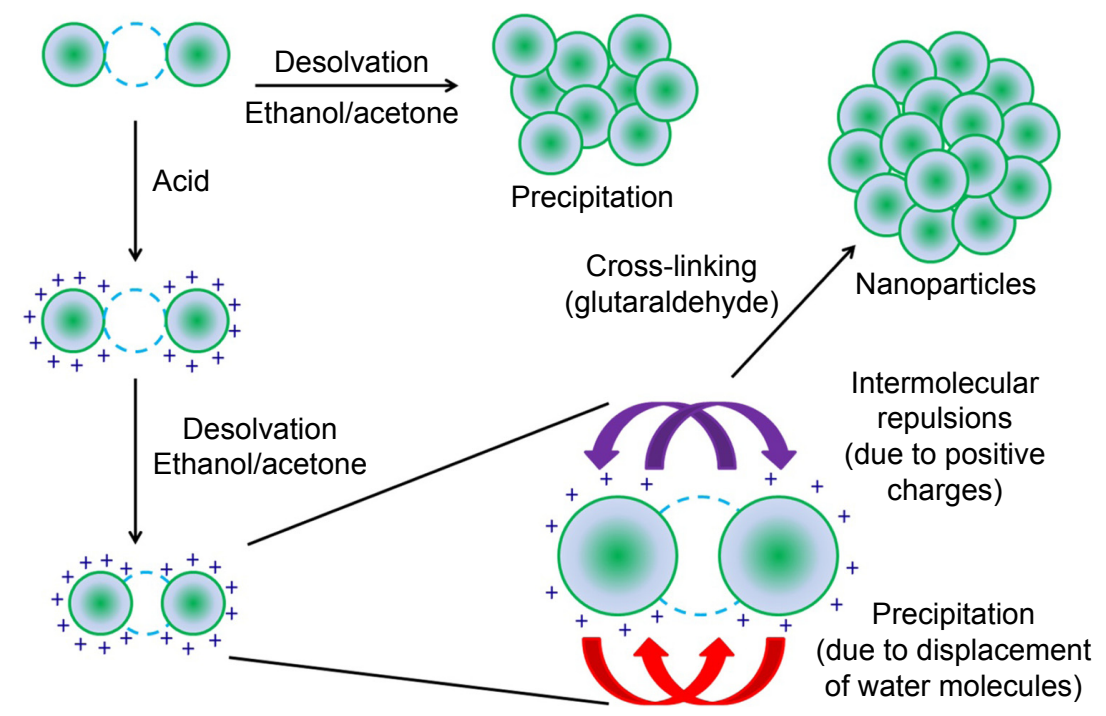

Scheme I Schematic representation of nanoparticle synthesis (a single desolvation step is shown).

Notes: Green circles represent gelatin molecules, and blue dotted circles represent water molecules. The addition of desolvation agent without adjusting the $\mathrm{pH}$ leads to precipitation of the protein. However, the addition of desolvation agent after adjusting the $\mathrm{pH}$ of the protein solution leads to a controlled precipitation of the protein leading to the formation of homogeneous nanoparticles (violet arrows indicate intermolecular repulsion due to the positive charges, while red arrows indicate precipitation induced by the addition of desolvating agent).

area to volume ratio, is an important parameter in governing the degradation kinetics and hence the drug release profiles. In addition to nanoparticle size, the matrix density of the particles should also govern the drug release profiles. Two parameters that are most likely to play an important role in regulating the matrix densities of the particles are, 1) the $\mathrm{pH}$ (which determines the charge on gelatin), and 2) the amount of desolvating agent added.

\section{Effect of $\mathrm{pH}$ on the surface charge of gelatin}

The $\mathrm{pH}$ before the desolvation step, as mentioned earlier, imparts a net positive or negative charge on gelatin, thereby inducing intra- and intermolecular repulsions in gelatin.
While a high surface charge leads to intermolecular repulsions and hence a stable suspension, a low surface charge may lead to precipitation.

As shown in Figure 1A and B, gelatin type A and type B show an increase in the zeta potential as the $\mathrm{pH}$ is lowered from the isoelectric point (pI) of gelatin. However, after reaching a peak value around $\mathrm{pH} 4$ and 3.5 (for gelatin type $\mathrm{A}$ and type $\mathrm{B}$, respectively), the zeta potential starts decreasing with further lowering of $\mathrm{pH}$.

The $\mathrm{pI}$ of gelatin type $\mathrm{A}$ and type $\mathrm{B}$ varies in the range of 7-9 and 4.7-5.2, respectively. A decrease in $\mathrm{pH}$ below the $\mathrm{pI}$ thus leads to an increase in the zeta potential of gelatin. A further decrease in $\mathrm{pH}$ below 4 may lead to the protonation of aspartic acid and glutamic acid ( $\mathrm{p} K_{\mathrm{a}}$ of 3.9 and 4.3, respectively),
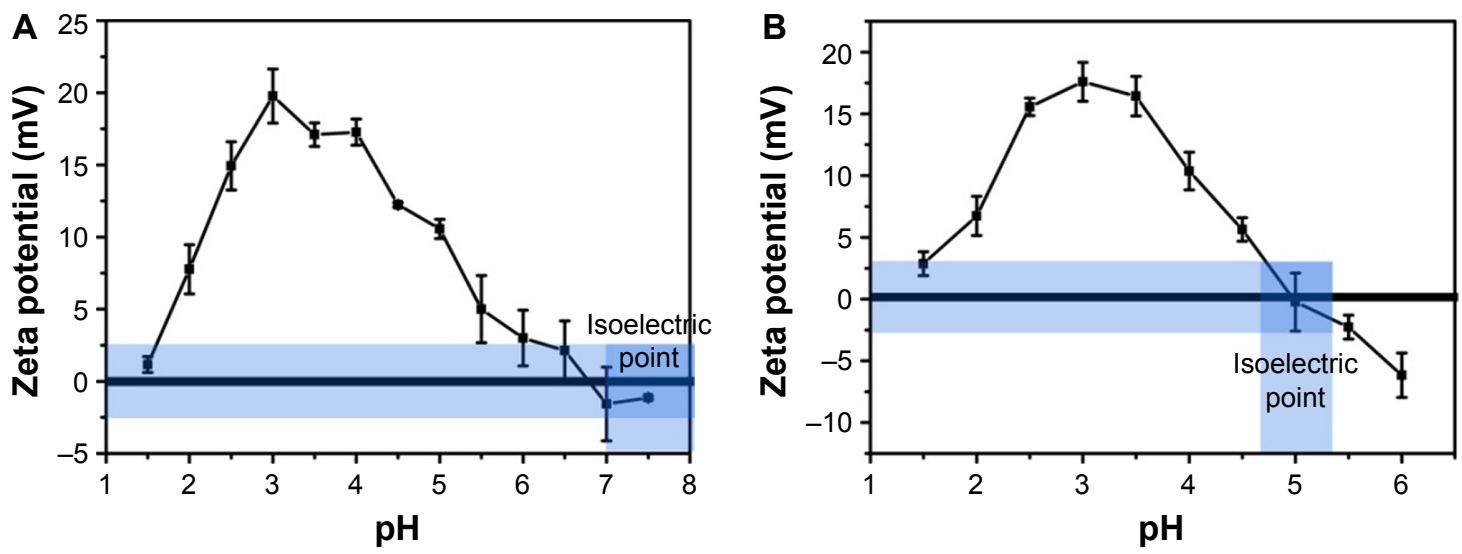

Figure I Variation in zeta potential of $(\mathbf{A})$ gelatin type $\mathrm{A}$ and $(\mathbf{B})$ gelatin type $\mathrm{B}$ with $\mathrm{pH}$. 
thereby accounting for the maximum zeta potential values observed at a $\mathrm{pH}$ of $\sim 4$ and 3.5 for type $\mathrm{A}$ and type $\mathrm{B}$ gelatin, respectively. However, a decrease in the zeta potential below this $\mathrm{pH}$ is unexpected and can be attributed to the counter ions $\left(\mathrm{Cl}^{-}\right)$added to the solution while adjusting the $\mathrm{pH}^{31,32}$ As the $\mathrm{p} K_{\mathrm{a}}$ values of all the amino acid side chains are above $\mathrm{pH} 3.5$, it can be assumed that at a $\mathrm{pH}$ below 3.5, all the side chains are maximally protonated and thus a further decrease in $\mathrm{pH}$ should, in principle, have no effect on the ionization state of the protein. As $\mathrm{HCl}$ is added for decreasing the $\mathrm{pH}$ of the gelatin solution, $\mathrm{Cl}^{-}$ions in the solution also increase. The introduction of anions may lead to ion pair formation and Debye-Huckel screening effect, thereby accounting for the decrease in the zeta potential of the protein. ${ }^{31}$

The possibility of an increase in surface hydrophobicity on gelatin molecules with decreasing $\mathrm{pH}$ was explored by incubating gelatin type B with a neutral dye, Nile Red..$^{33}$ Nile Red binding remained low and constant with varying $\mathrm{pH}$ (Figure S1), thereby indicating no alteration in surface hydrophobicity.

\section{Precipitation of gelatin by acetone: formation of nanoparticles}

Acetone was utilized as a desolvating agent. The gradual addition of acetone leads to an increase in turbidity of the gelatin solution indicating the formation of nanoparticles. The amount of acetone required to precipitate gelatin varies and is dependent on the $\mathrm{pH}$ of the gelatin solution. Figure 2A shows the percentage of acetone required to initiate precipitation in gelatin type B solutions incubated at different $\mathrm{pH}$ values. Solutions incubated at $\mathrm{pH}$ values close to the $\mathrm{pI}$ of gelatin require lesser acetone $(\sim 55 \%$ acetone for gelatin at $\mathrm{pH} 4$ ) for precipitation. However, as the $\mathrm{pH}$ is varied away from the $\mathrm{pI}$ of gelatin, the amount of acetone required to precipitate gelatin increases $(\sim 73 \%$ acetone for gelatin at $\mathrm{pH} 3.25)$.

The process of GNP synthesis involves a controlled precipitation, where the force of precipitation driven by the removal of water molecules is balanced by intermolecular charge repulsions induced by the altered $\mathrm{pH}$. Apart from this, the increase in the water-holding capacity of gelatin at low $\mathrm{pH}$ may also lead to an increase in the acetone concentrations required.
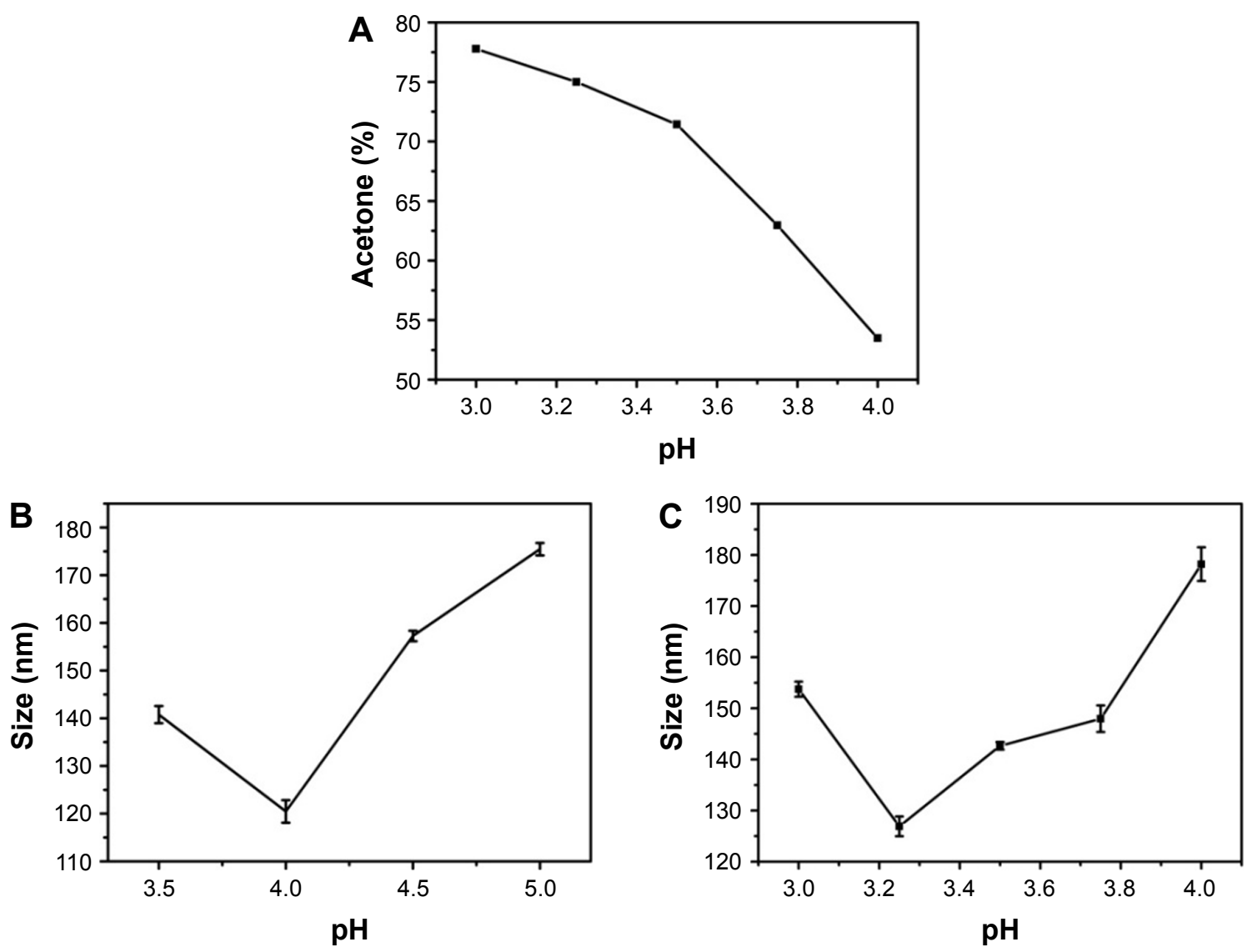

Figure 2 (A) Acetone (\%) required for the precipitation of gelatin solutions maintained at different $\mathrm{pH}$ values. (B) Effect of pH on nanoparticle size prepared from gelatin type A. (C) Effect of $\mathrm{pH}$ on nanoparticle size prepared from gelatin type $\mathrm{B}$. 
The decrease in $\mathrm{pH}$ also has an effect on the waterholding capacity of gelatin molecules. In regular $\alpha$-helices and $\beta$-sheets, the $\mathrm{NH}$ and $\mathrm{CO}$ groups of the peptide backbone are involved in intramolecular hydrogen bonding. However, the formation of triple helical structures in gelatin results in the availability of $\mathrm{CO}$ and $\mathrm{NH}$ groups (of the peptide backbone) which may also be involved in hydrogen bonding (Figure S2). ${ }^{34} \mathrm{~A}$ decrease in $\mathrm{pH}$ may lead to an increase in the interaction of the hydrophilic segments in gelatin with the solvating water molecules. A low $\mathrm{pH}$ thus makes the hydration network in gelatin more extensive and stronger. ${ }^{35,36}$ Moreover, the inter- and intra-chain interactions in gelatin arising either directly or through water-mediated hydrogen bonding (Figure S2) may increase its water retention capacity, thereby accounting for the increased amount of acetone required to initiate phase separation, precipitation and nanoparticle formation in gelatin.

We further elucidated the effect of zeta potential variations on GNP size. Nanoparticles were synthesized at different $\mathrm{pH}$ values for both gelatin type A and type B. Nanoparticles synthesized at $\mathrm{pH}$ values close to the $\mathrm{pI}$ (7-9 for gelatin type A and 4.7-5.2 for gelatin type B) were large and unstable with a tendency to aggregate. However, nanoparticles synthesized below $\mathrm{pH} 4$ were small and stable with a low polydispersity index (PDI). As shown in Figure 2B and C, a trend of decreasing particle size with decreasing $\mathrm{pH}$ was observed until $\mathrm{pH} 4$ for gelatin type A and $\mathrm{pH} 3.25$ for gelatin type B. However, decreasing the $\mathrm{pH}$ below these values resulted in an increase in nanoparticle size. Nanoparticle formation was not possible at a $\mathrm{pH}$ below 3.5 for gelatin type $\mathrm{A}$ and $\mathrm{pH}$ below 3.0 for gelatin type B. Even a high concentration of desolvating agent failed to induce precipitation in gelatin at these low $\mathrm{pH}$ values. However, there are a few reports of nanoparticle synthesis at a $\mathrm{pH}$ as low as 2.5 for gelatin type A. ${ }^{5,26}$ This could be due to molecular crowding because of the significantly

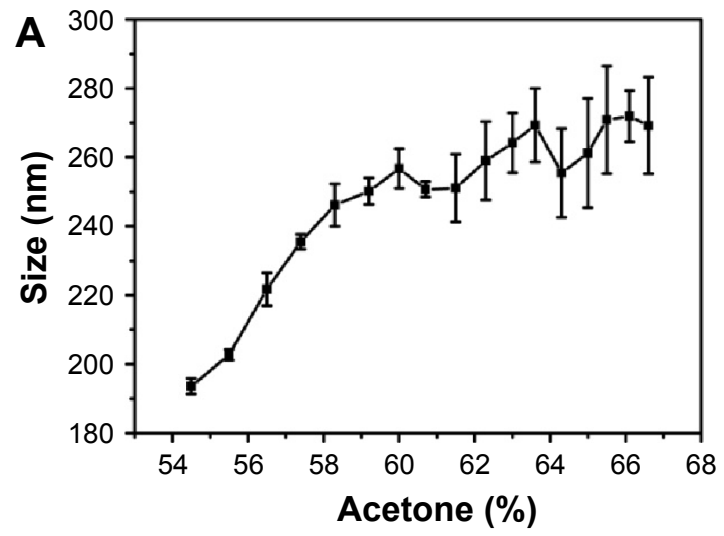

higher concentration of gelatin used. Moreover, an increase in gelatin concentration is known to increase its viscosity, ${ }^{37}$ which may promote nanoparticle formation at low $\mathrm{pH}$ and was also observed to increase the nanoparticle size (Figure S3). In the current study, gelatin type A and type B were used at a concentration of $1 \%$, which failed to precipitate at $\mathrm{pH}$ values below 3.5 and 3, irrespective of the amount of acetone used.

Shutava et $\mathrm{a}^{25}$ have reported a similar trend in nanoparticle size variation with decreasing $\mathrm{pH}$. While the decrease in the size of the nanoparticles as the $\mathrm{pH}$ is reduced below the $\mathrm{pI}$ of the protein is attributed to the effective precipitation of gelatin, the increase in particle size with a further decrease in $\mathrm{pH}$ ( $\mathrm{pH}$ below 4 for gelatin type $\mathrm{A}$ and $\mathrm{pH}$ below 3.25 for gelatin type B) has been attributed to a decrease in solution viscosity. However, we suggest that apart from the viscosity, the surface charge on gelatin may also play an important role in determining the particle size. As shown in Figure 1, the zeta potential of gelatin type A and B reaches a maximum value around $\mathrm{pH} 4$ and 3.5, respectively. Below these $\mathrm{pH}$ values, as the zeta potential starts decreasing, the particles size starts increasing, suggesting a decrease in repulsive forces and hence an increase in the precipitation tendency of gelatin. This could be the possible reason why nanoparticles formed at these extremely low $\mathrm{pH}$ values tend to have a larger size than the nanoparticles synthesized at $\mathrm{pH} 4$ and 3.25 for gelatin type A and type B, respectively.

\section{Mechanism of nanoparticle assembly at low and high $\mathrm{pH}$}

As mentioned earlier, the amount of acetone (desolvating agent) required for nanoparticle synthesis varies depending upon the $\mathrm{pH}$ of the solution. We, therefore, investigated the effect of acetone concentration on the particle size in an attempt to gain insights into the mechanism of nanoparticle assembly at different $\mathrm{pH}$ values. Figure $3 \mathrm{~A}$ shows the size

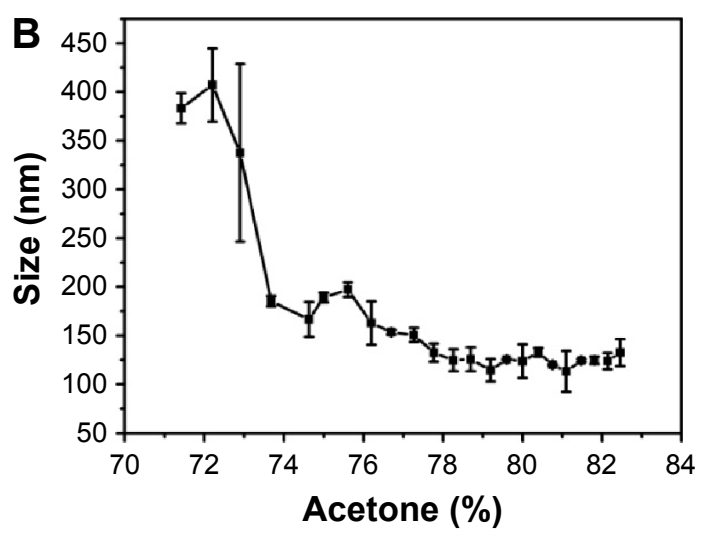

Figure 3 Effect of acetone concentration on gelatin (type B) nanoparticle size prepared at pH $4(\mathbf{A})$ and $\mathrm{pH} 3.25$ (B). 
variation in gelatin (type B) nanoparticles, prepared at $\mathrm{pH} 4$, as a function of acetone concentration. As evident from Figure $3 \mathrm{~A}$, precipitation is initiated at $\sim 50 \%-55 \%$ of acetone and the nanoparticle size increases with increasing acetone concentration. Weber et $\mathrm{al}^{29}$ suggested that the desolvation process by the addition of acetone can be divided into two parts: in the initial part, nanoparticle size increases with an increase in acetone concentration while in the later part, the number of particles increase upon acetone addition. As shown in Figure 3A, the particle size gradually increases with acetone (until $\sim 60 \%$ ), then remains constant with no significant change. While the biphasic behavior of nanoparticle formation observed in the current study is consistent with the findings of Weber et al, we found that the second phase is characterized by an increase in the PDI of the nanoparticles which suggests, 1) addition of free gelatin to preformed nanoparticles, 2) a further removal of water from the preformed nanoparticles, and 3 ) interparticle aggregation due to low surface charges. We propose that the nanoparticle formation at $\mathrm{pH} 4$ takes place via the formation of a dense core during the initial phase which may act as a nucleus upon which additional gelatin molecules are added by the further addition of acetone (Figure 4A). The whole process results in the formation of nanoparticles with a highly dense matrix as shown in Figure 4B.

In contrast to the nanoparticles synthesized at $\mathrm{pH} 4$, those synthesized at $\mathrm{pH} 3.25$ appear to follow a completely different mechanism of particle assembly. As shown in Figure 3B, we observed a decrease in particle size upon the addition of acetone. At pH 3.25, perhaps due to enhanced water retention capacity of gelatin and an incomplete extraction of water molecules by acetone, the nanoparticles formed were larger. However, with a further increase in acetone concentration, we observed a decrease in nanoparticle size. We propose that the initial particles formed, at low concentrations of acetone at $\mathrm{pH} 3.25$, are large followed by a condensation of the particles with further increase in acetone concentration. This leads to a reduction in nanoparticle size along with the addition of new particles in the solution. Even the addition of excess acetone (beyond 78\%) had no effect on the particle size and polydispersity. The particles synthesized at $\mathrm{pH} 3.25$, thus, tend to have a less dense matrix as shown in Figure 4C and D.

From the current set of experiments, we conclude that the combined effect of $\mathrm{pH}$ and acetone determines the matrix density in addition to the particle size and number. The differences in the assembly of nanoparticles might be responsible for the differences in the matrix density observed.

The process of nanoparticle assembly can also be explained based on the desolvation barrier model proposed for protein folding by Cheung et al. ${ }^{9}$ They suggest that the process of protein folding via the desolvation model takes place through a partially hydrated, less stable state. The two minima (Figure 4E) in the potential energy curve represent either a stable water-mediated interaction or a stable direct interaction (between two different protein molecules or within the same protein molecule). In the context of GNP synthesis, the two minima may be a hydrated state and a precipitated state. Nanoparticles may occupy the region between the two minima, on the desolvation barrier. These nanoparticles are energetically in a less favorable state. Nanoparticles isolated at this level may either aggregate or dissolve. Glutaraldehyde cross-linking preserves these nanoparticles (Figure 4E).

\section{Evaluating the protease susceptibility of the GNPs synthesized with different matrix densities}

We synthesized nanoparticles with varying matrix densities with a rationale to develop nanoparticles with varying matrix densities. Figure 4B and D shows the pictures of the nanoparticles, in equal quantities $\left(10 \mathrm{mg} \mathrm{mL}^{-1}\right)$. The nanoparticles synthesized at $\mathrm{pH} 4$ were found to be more turbid compared to the ones synthesized at $\mathrm{pH} 3.25$. The hydrodynamic diameter of the nanoparticles synthesized at $\mathrm{pH} 3.25$ and 4 was found to be $185.2 \pm 5.2 \mathrm{~nm}$ and $235.5 \pm 2.2 \mathrm{~nm}$, respectively, with a PDI of $<0.2$.

We then studied the protease-induced degradation of GNPs synthesized at $\mathrm{pH} 3.25$ with LMD-GNPs and at $\mathrm{pH} 4$ with HMD-GNPs, by monitoring the light scatter at $465 \mathrm{~nm}$ in a fluorescence spectrophotometer. The degradation kinetics of nanoparticles with an LMD (Figure 5, black line) was faster as compared to the nanoparticles synthesized with a HMD (Figure 5, gray line).

Modulating the susceptibility of protein-based nanoparticles toward proteases can be an efficient tool for regulating nanoparticle degradation and hence drug release. The differences in degradation kinetics of the two nanoparticle systems described in the current study can thus be utilized to regulate drug release. Such a system can be specifically advantageous in conditions such as aggressive cancers ${ }^{38}$ and keratitis,${ }^{39}$ where the protease concentration in the microenvironment is dependent on the severity of the pathological situation. By carefully utilizing such a system, the drug release can be modulated more efficiently.

\section{Evaluation of fluorescein loading and release from nanoparticles synthesized with varying matrix densities}

To evaluate the LE of nanoparticles, fluorescein-loaded LMDGNPs and HMD-GNPs were weighed and resuspended in PBS 
A
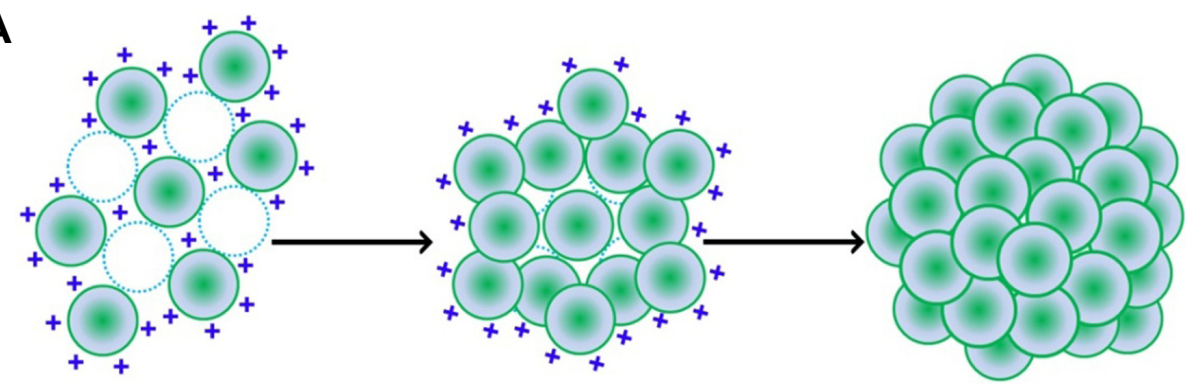

C

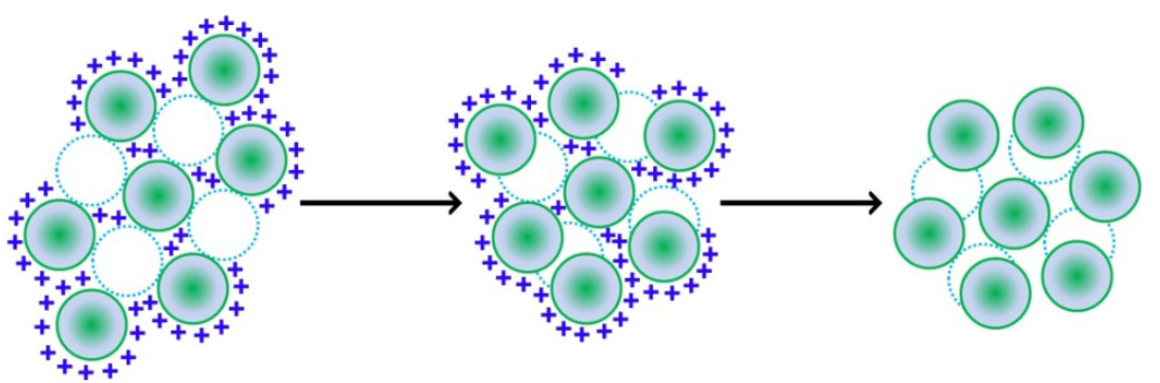

B

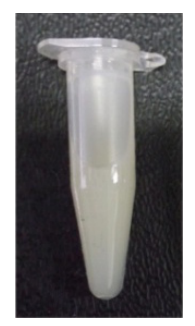

D

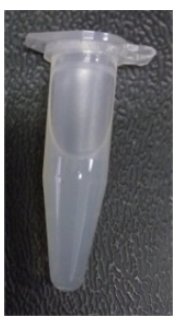

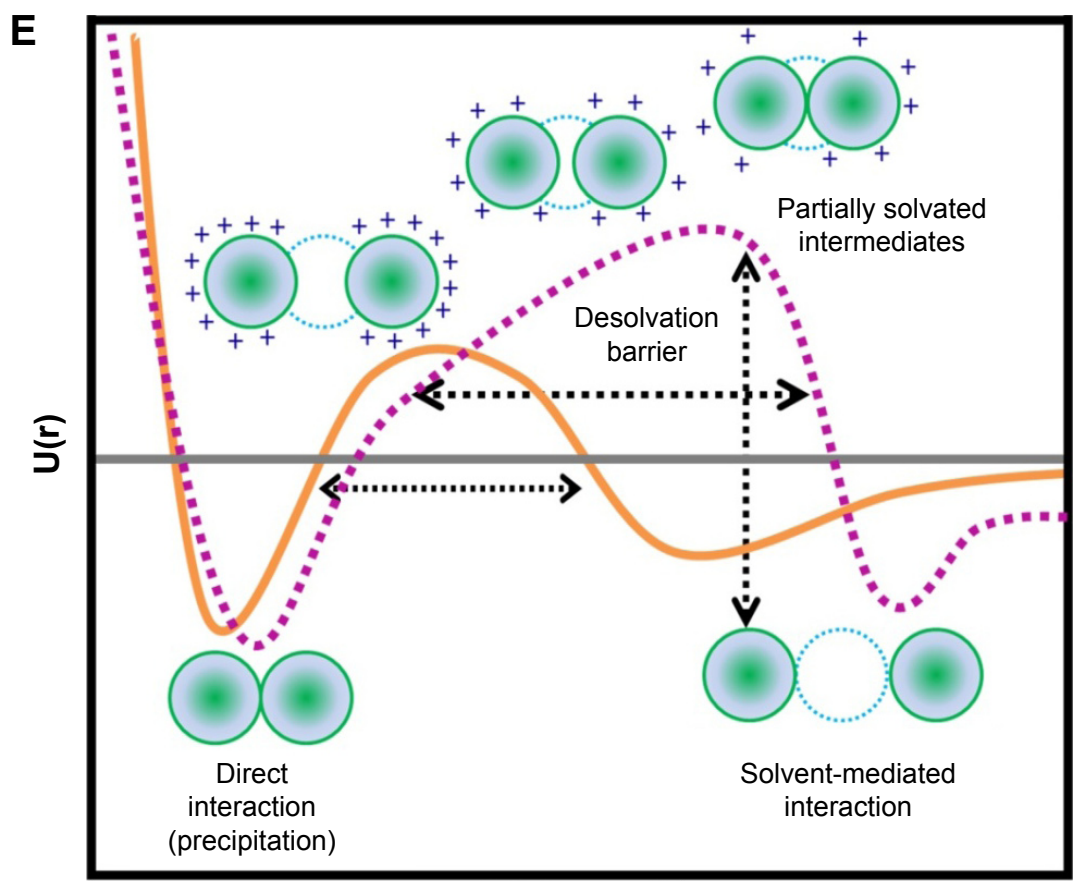

Distance ( $r)$

Figure 4 Mechanism of GNP synthesis at $(\mathbf{A}) \mathrm{pH} 4$ and $(\mathbf{C}) \mathrm{pH}$ 3.25. Micrographs of GNPs synthesized at (B) pH 4 with HMD and (D) pH 3.25 with LMD. (E) Schematic representation of the potential energy function $(\mathrm{U}(\mathrm{r})$ ) in the desolvation model. In this model, a native interaction between two gelatin residues (green spheres) can be either direct or mediated by a water molecule (blue dashed circle). Orange curve represents the potential energy function for gelatin protein during desolvation. Dashed purple curve represents the potential energy function for gelatin under conditions of nanoparticle synthesis. The "+" represents the positive surface charge on the molecule ([E] Adapted from Cheung MS, Garcia AE, Onuchic JN. Protein folding mediated by solvation: Water expulsion and formation of the hydrophobic core occur after the structural collapse. Proc Natl Acad Sci USA. 2002;99[2]:685-690. Copyright [2002] National Academy of Sciences, USA. ${ }^{9}$ ).

Abbreviations: GNPs, gelatin nanoparticles; HMD, high matrix density; LMD, low matrix density.

The particles were subsequently digested with pronase, and the amount of fluorescein released was estimated by monitoring the absorbance at $492 \mathrm{~nm}$ and comparison to fluorescein standards. The LE for LMD-GNPs and HMD-GNPs was found to be $52.2 \% \pm 2.3 \%$ and $46.3 \% \pm 3.5 \%$, respectively.
The slight difference in the LEs of the two types of GNPs is possibly due to the high porosity of the LMD-GNPs and hence more free space to accommodate fluorescein.

The rate of fluorescein release from GNPs synthesized with varying matrix densities was evaluated. The nanoparticle 
A

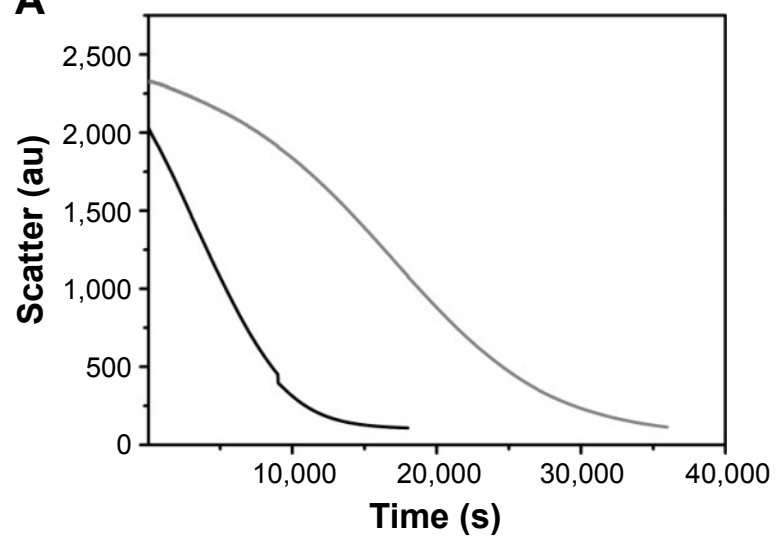

B

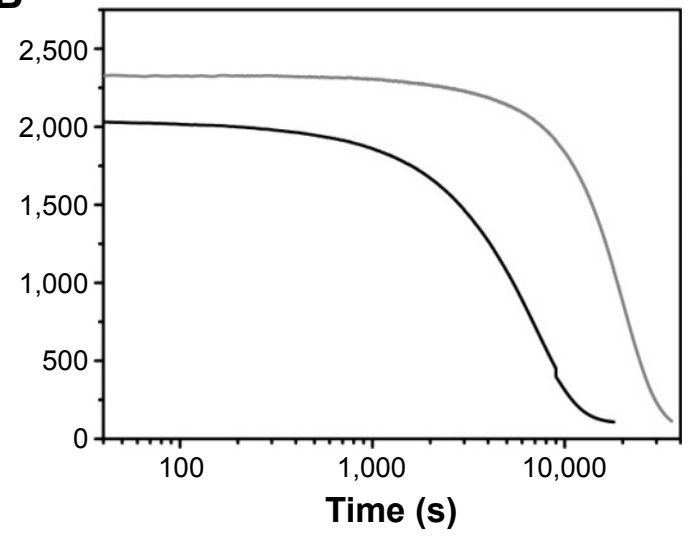

Figure 5 Protease degradation of nanoparticles with HMD (gray) and LMD (black). Notes: (A) Linear scale and (B) log scale.

Abbreviations: HMD, high matrix density; LMD, low matrix density; s, seconds.

solution was supplemented with varying concentrations of pronase to induce particle degradation. As shown in Figure 6, the fluorescein release from the GNPs synthesized with different matrix densities followed a different release profile. In the absence of pronase (Figure 6A), there was an initial burst (first 30 minutes) release of fluorescein from both the particles. However, the release from LMD-GNPs was more $(44.6 \% \pm 1.3 \%)$ as compared to that from HMD-GNPs $(31.7 \% \pm 1.0 \%)$. The higher burst release from the LMDGNPs could be attributed to the high porosity of these particles and the effect of a mild sonication to disperse these particles prior to the experiment.

In the presence of low concentrations of pronase (100 ng mL $\mathrm{mL}^{-1}$; Figure 6B), the release profile of fluorescein showed a clear difference between LMD-GNPs and HMDGNPs. While LMD-GNPs showed an initial burst (first 30 minutes) of $72.3 \% \pm 0.7 \%$ release, the burst release in the case of HMD-GNPs was found to be $53.1 \% \pm 1.8 \%$. However, the release of fluorescein from HMD-GNP was found to be slow and sustained over a period of $18 \mathrm{~h}(98.0 \% \pm 2.3 \%)$ compared to a $95.5 \% \pm 4.3 \%$ fluorescein release from LMDGNPs in the first $6 \mathrm{~h}$.

However, in the presence of a higher amount of pronase $\left(1 \mu \mathrm{g} \mathrm{mL}^{-1}\right)$, the fluorescein release profiles from both the particles were similar with a slight retardation of fluorescein release in the case of HMD-GNPs (Figure 6C).

\section{GNP clearance by mouse macrophage (RAW 264.7) cell line}

To evaluate the intracellular degradation and fluorescein release from GNPs, RAW 264.7 cells were treated with fluorescein-loaded LMD-GNPs and HMD-GNPs. The cells were then visualized under a confocal microscope at indicated time points. As shown in Figure 7, both LMD-GNPs and HMD-GNPs (green fluorescence) were rapidly taken up by the cells and localized with the lysosomes (red fluorescence) at the $0 \mathrm{~h}$ time point. At later time points, viz $8 \mathrm{~h}$ and $16 \mathrm{~h}$, the nanoparticle-associated fluorescence was found
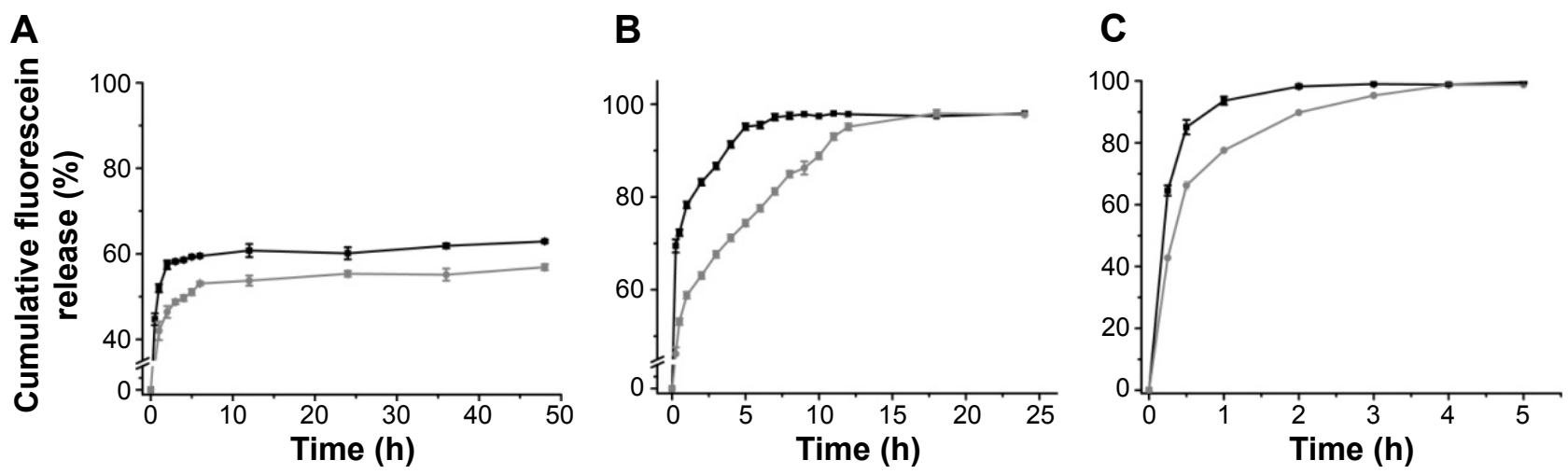

Figure 6 Fluorescein release from GNPs with (A) $0 \mathrm{mg} \mathrm{mL}^{-1}$ pronase, (B) $100 \mathrm{ng} \mathrm{mL}^{-1}$ pronase and (C) I $\mu \mathrm{g} \mathrm{mL}^{-1}$ pronase.

Notes: Black and gray curves represent cumulative fluorescein release from GNPs of LMD and HMD, respectively.

Abbreviations: GNPs, gelatin nanoparticles; HMD, high matrix density; LMD, low matrix density; h, hours. 


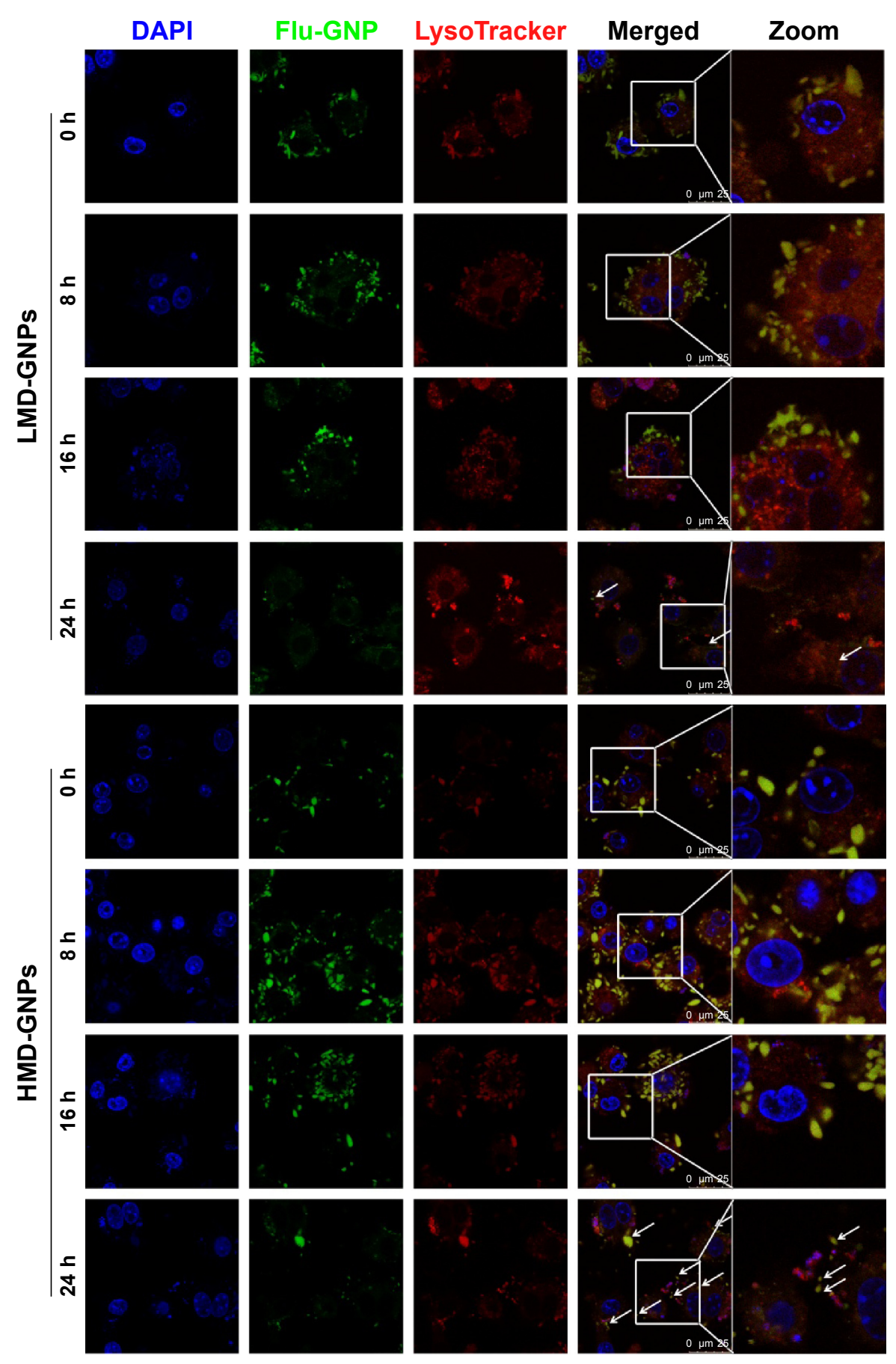

Figure 7 Clearance of GNPs in RAW 264.7 cell line.

Notes: Fluorescein-loaded GNPs were incubated with RAW 264.7 cells for $2 \mathrm{~h}$ under normal culture conditions. The cells were then washed and incubated further for indicated time points $(0 \mathrm{~h}, 8 \mathrm{~h}, 16 \mathrm{~h}$ and $24 \mathrm{~h})$. At the indicated time points, cells were treated with LysoTracker-Red for 30 min and then washed and fixed with $4 \%$ formaldehyde. Cells were counterstained with DAPI and observed under a confocal fluorescence microscope. The last panel provides a zoomed image of the area represented in white boxes in the merged panel. White arrows at the $24 \mathrm{~h}$ time point in LMD-GNPs indicate a diffused dye-associated fluorescence suggesting nanoparticle degradation, while the white arrows at the $24 \mathrm{~h}$ time point in HMD-GNPs indicate a punctate nanoparticle-associated fluorescence suggesting the slow degradation rates of HMD-GNPs as compared to LMD-GNPs.

Abbreviations: DAPI, 4',6-diamidino-2-phenylindole; Flu-GNP, fluorescein loaded gelatin nanoparticles; GNPs, gelatin nanoparticles; HMD, high matrix density; LMD, low matrix density; h, hours.

to be similar in the LMD-GNPs- and HMD-GNP-treated cells. However, at the $24 \mathrm{~h}$ time point, cells treated with LMD-GNPs showed more diffused fluorescence compared to the HMD-GNP-treated cells, where particle-associated fluorescence was still visible (Figure 7, white arrows). The diffused fluorescence in the case of LMD-GNP-treated cells is indicative of nanoparticle degradation and fluorescein release. It could be thus concluded that the intracellular 
degradation of LMD-GNPs was significantly faster compared to HMD-GNPs.

\section{Conclusion}

Gelatin due to its extensive hydration network holds 5-10 times its weight of water. The extraction of these water molecules by a desolvating agent, under extreme $\mathrm{pH}$ values, forms the basis of the desolvation process utilized in GNP synthesis. We found that the $\mathrm{pH}$ at which gelatin is incubated determines the mechanism by which nanoparticles are formed. By altering the $\mathrm{pH}$, hence the mechanism, it is possible to synthesize nanoparticles with different matrix densities. These nanoparticles when subjected to proteasebased degradation show varying degradation susceptibility. They also show minor variations in the drug-loading efficiencies. However, they show significant differences in intra- and extracellular drug release rates. We believe that the current study should prove useful in designing GNPs with a variable response to proteases and aid in providing a better regulation over drug release rates.

\section{Acknowledgments}

This work was supported by the Department of Science and Technology (DST), Government of India funded project, Nanotechnology for biomedical applications. SMA acknowledges the Council for Scientific and Industrial Research (CSIR) for financial support. MRC acknowledges the funding from the Sir JC Bose National Fellowship of the Department of Science and Technology (DST), India.

\section{Disclosure}

The authors report no conflicts of interest in this work.

\section{References}

1. Maham A, Tang Z, Wu H, Wang J, Lin Y. Protein-based nanomedicine platforms for drug delivery. Small. 2009;5(15):1706-1721.

2. Weber C, Reiss S, Langer K. Preparation of surface modified protein nanoparticles by introduction of sulfhydryl groups. Int J Pharm. 2000; 211(1-2):67-78.

3. Balthasar S, Michaelis K, Dinauer N, von BH, Kreuter J, Langer K. Preparation and characterisation of antibody modified gelatin nanoparticles as drug carrier system for uptake in lymphocytes. Biomaterials. 2005;26(15):2723-2732.

4. Coester C, Kreuter J, von BH, Langer K. Preparation of avidin-labelled gelatin nanoparticles as carriers for biotinylated peptide nucleic acid (PNA). Int J Pharm. 2000;196(2):147-149.

5. Coester CJ, Langer K, van BH, Kreuter J. Gelatin nanoparticles by two step desolvation - a new preparation method, surface modifications and cell uptake. J Microencapsul. 2000;17(2):187-193.

6. Marty JJ, Oppenheim RC, Speiser P. Nanoparticles: a new colloidal drug delivery system. Pharm Acta Helv. 1978;53:17-23.

7. Rank JA, Baker D. A desolvation barrier to hydrophobic cluster formation may contribute to the rate-limiting step in protein folding. Protein Sci. 1997; 6:347-354.
8. Aksel T, Majumdar A, Barrick D. The contribution of entropy, enthalpy, and hydrophobic desolvation to cooperativity in repeat-protein folding. Structure. 2011;19(3):349-360.

9. Cheung MS, Garcia AE, Onuchic JN. Protein folding mediated by solvation: Water expulsion and formation of the hydrophobic core occur after the structural collapse. Proc Natl Acad Sci USA. 2002;99(2): 685-690.

10. Dumetz AC, Chockla AM, Kaler EW, Lenhoff AM. Protein phase behavior in aqueous solutions: crystallization, liquid-liquid phase separation, gels, and aggregates. Biophys J. 2008;94(2):570-583.

11. Mohanty B, Bohidar HB. Microscopic structure of gelatin coacervates. Int J Biol Macromol. 2005;36(1-2):39-46.

12. Wartlick H, Spankuch-Schmitt B, Strebhardt K, Kreuter J, Langer K. Tumour cell delivery of antisense oligonuclceotides by human serum albumin nanoparticles. J Control Release. 2004;96(3):483-495.

13. Kommareddy S, Amiji MM. Protein nanospheres for gene delivery. CSH Protoc. 2008;2008:db.to30.

14. Megeed Z, Cappello J, Ghandehari H. Genetically engineered silkelastinlike protein polymers for controlled drug delivery. Adv Drug Deliv Rev. 2002;54:1075-1091.

15. Langer K, Anhorn MG, Steinhauser I, et al. Human serum albumin (HSA) nanoparticles: reproducibility of preparation process and kinetics of enzymatic degradation. Int J Pharm. 2008;347(1-2):109-117.

16. Irache JM, Bergougnoux L, Ezpeleta I, Gueguen J, Orecchioni A-M. Optimization and in vitro stability of legumin nanoparticles obtained by a coacervation method. Int J Pharm. 1995;126:103-109.

17. Podaralla S, Perumal O. Preparation of zein nanoparticles by $\mathrm{pH}$ controlled nanoprecipitation. J Biomed Nanotechnol. 2010;6(4):312-317.

18. Teng Z, Luo Y, Wang Q. Nanoparticles synthesized from soy protein: preparation, characterization, and application for nutraceutical encapsulation. J Agric Food Chem. 2012;60(10):2712-2720.

19. Elzoghby AO, Helmy MW, Samy WM, Elgindy NA. Novel ionically crosslinked casein nanoparticles for flutamide delivery: formulation, characterization, and in vivo pharmacokinetics. Int $J$ Nanomedicine. 2013;8:1721-1732.

20. Herrera Estrada LP, Champion JA. Protein nanoparticles for therapeutic protein delivery. Biomater Sci. 2015;3(6):787-799.

21. Wetzel R, Buder E, Hermel H, Hüttner A. Conformations of different gelatins in solutions and in films an analysis of circular dichroism (CD) measurements. Colloid Polym Sci. 1987;265:1036-1045.

22. Djabourov M, Lechaire JP, Gaill F. Structure and rheology of gelatin and collagen gels. Biorheology. 1993;30:191-205.

23. Brodsky B, Persikov AV. Molecular structure of the collagen triple helix. Adv Protein Chem. 2005;70:301-339.

24. Lloyd DJ, Pleass WB. The absorption of water by gelatin. Biochem J. 1927;21:1352-1367.

25. Shutava TG, Balkundi SS, Vangala $P$, et al. Layer-by-layer-coated gelatin nanoparticles as a vehicle for delivery of natural polyphenols. ACS Nano. 2009;3(7):1877-1885.

26. Wong C, Stylianopoulos T, Cui J, et al. Multistage nanoparticle delivery system for deep penetration into tumor tissue. Proc Natl Acad Sci USA. 2011;108(6):2426-2431.

27. Farrugia CA, Groves MJ. Gelatin behaviour in dilute aqueous solution: designing a nanoparticulate formulation. J Pharm Pharmacol. 1999; 51(6):643-649.

28. Uhrich KE, Cannizzaro SM, Langer RS, Shakesheff KM. Polymeric systems for controlled drug release. Chem Rev. 1999;99:3181-3198.

29. Weber C, Coester C, Kreuter J, Langer K. Desolvation process and surface characterisation of protein nanoparticles. Int J Pharm. 2000; 194(1):91-102.

30. Azarmi S, Huang Y, Chen H, et al. Optimization of a two-step desolvation method for preparing gelatin nanoparticles and cell uptake studies in 143B osteosarcoma cancer cells. J Pharm Pharm Sci. 2006; 9(1):124-132.

31. Goto Y, Takahashi N, Fink AL. Mechanism of acid-induced folding of proteins. Biochemistry. 1990;29(14):3480-3488.

32. Goto Y, Calciano LJ, Fink AL. Acid-induced folding of proteins. Proc Natl Acad Sci USA. 1990;87(2):573-577. 
33. Sackett DL, Wolff J. Nile red as a polarity-sensitive fluorescent probe of hydrophobic protein surfaces. Anal Biochem. 1987;167(2):228-234.

34. Brodsky B, Ramshaw JA. The collagen triple-helix structure. Matrix Biol. 1997;15(8-9):545-554.

35. Koli JM, Basu S, Kannuchamy N, Gudipati V. Effect of $\mathrm{pH}$ and ionic strength on functional properties of fish gelatin in comparison to mammalian gelatin. Fish Technol. 2013;50:126-132.

36. Nurul AG, Sarbon NM. Effects of $\mathrm{pH}$ on functional, rheological and structural properties of eel (Monopterus sp.) skin gelatin compared to bovine gelatin. Int Food Res J. 2015;22:572-583.
37. Cumper CWN, Alexander AE. The viscosity and rigidity of gelatin in concentrated aqueous systems. I. Viscosity. Aust J Sci Res. 1952;5:146-152.

38. Kohrmann A, Kammerer U, Kapp M, Dietl J, Anacker J. Expression of matrix metalloproteinases (MMPs) in primary human breast cancer and breast cancer cell lines: new findings and review of the literature. BMC Cancer. 2009;9:188.

39. Gopinathan U, Ramakrishna T, Willcox M, et al. Enzymatic, clinical and histologic evaluation of corneal tissues in experimental fungal keratitis in rabbits. Exp Eye Res. 2001;72(4):433-442. 


\section{Supplementary materials}

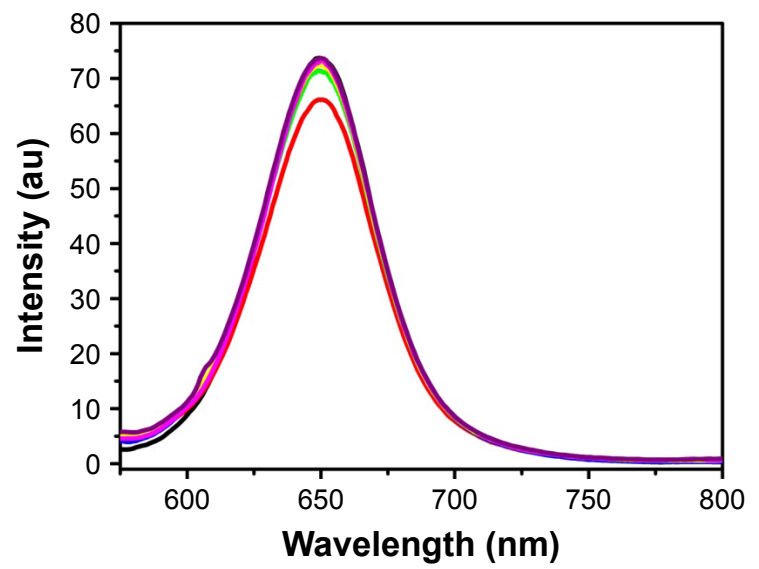

Figure SI Nile Red binding to gelatin type $\mathrm{B}$ at different $\mathrm{pH}$ values.

Note: Water (black), pH 2.5 (red), pH 3 (blue), pH 3.5 (green), pH 4 (orange), pH 4.5 (yellow), pH 5 (magenta) and pH 5.5 (violet).

Abbreviation: Nile Red, 9-diethylamino-5H-benzo[ $\alpha]$ phenoxazine-5-one.

\section{A}

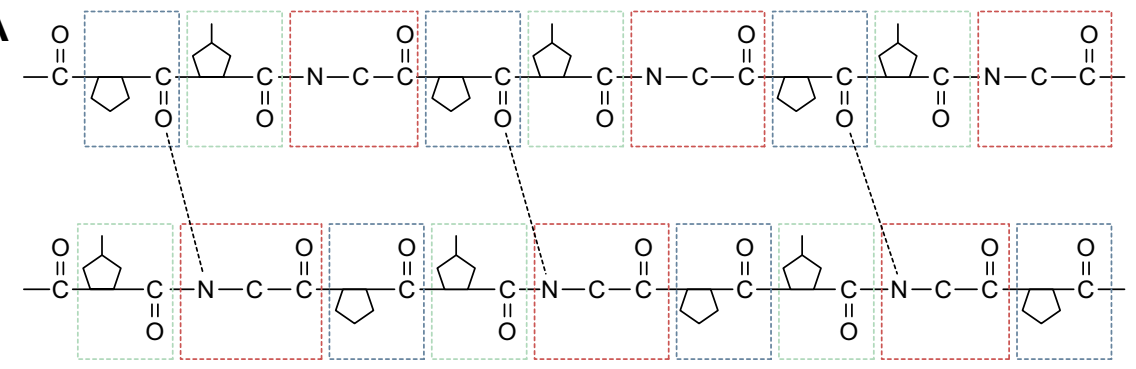

Direct hydrogen bonding (Gly) NH-CO (Pro)

B

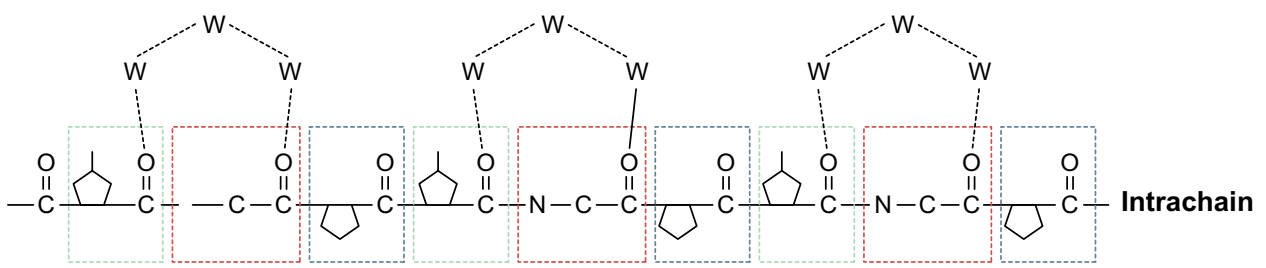

C

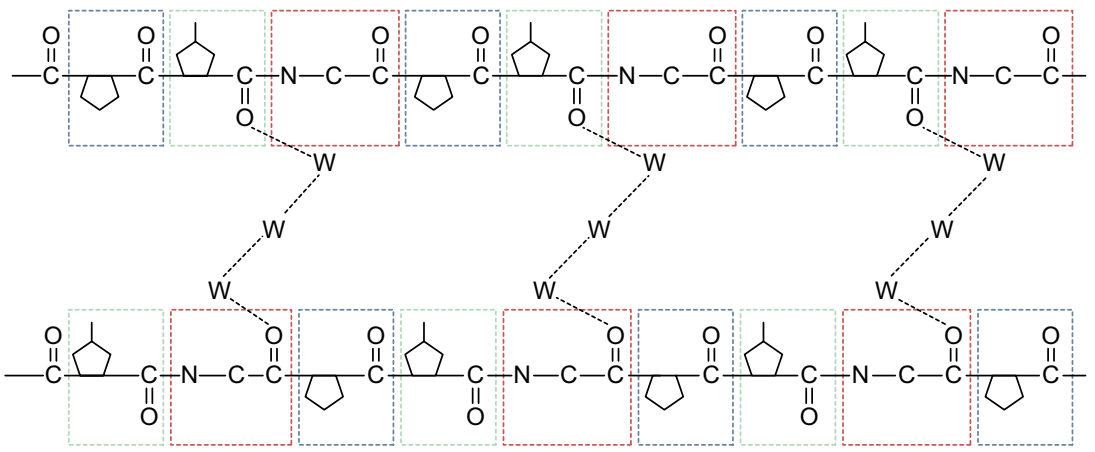

Water-mediated hydrogen bonding linking carbonyl groups CO (Hyp)-W-CO (Gly)

Figure S2 (Continued) 


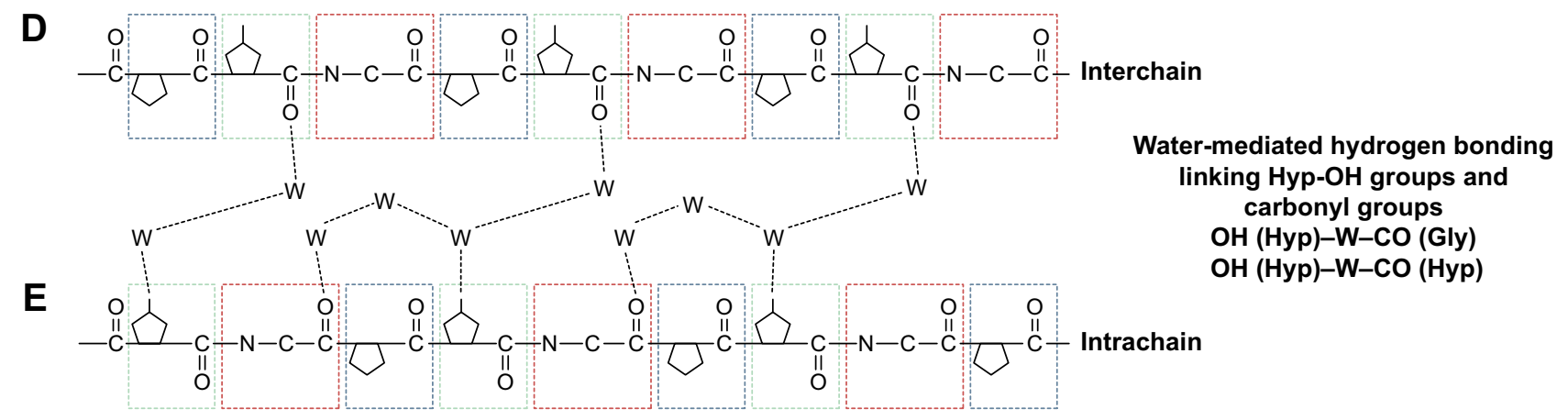

Figure S2 Schematic illustration of hydrogen bonding in gelatin.

Notes: (A) Direct interchain hydrogen bonding. (B) Water-mediated intra-chain hydrogen bonding. (C) Water-mediated interchain H-bonding. (D) and (E) Water-mediated inter- and intra-chain H-bonding (Adapted from Matrix Biol, I5[8-9], Brodsky B, Ramshaw JA, The collagen triple-helix structure, 545-554, Copyright [1997], with permission from Elsevier.').

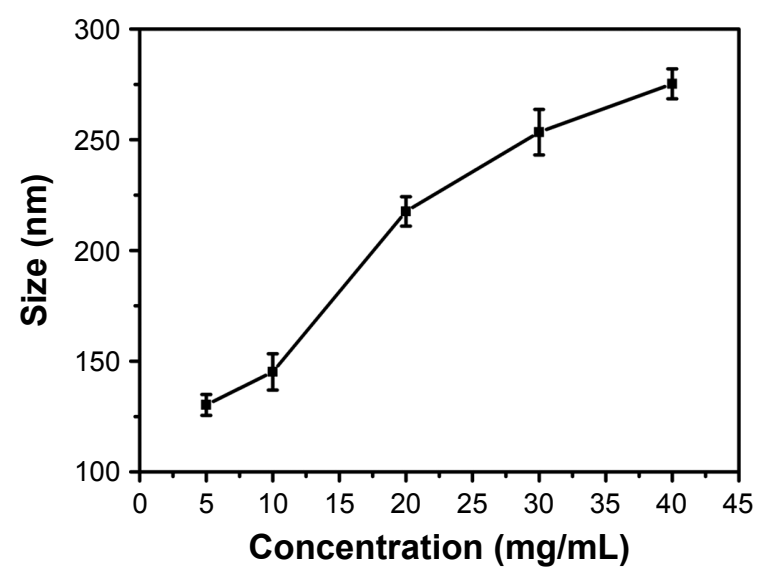

Figure S3 Effect of gelatin concentration on nanoparticle size.

\section{Reference}

1. Brodsky B, Ramshaw JA. The collagen triple-helix structure. Matrix Biol. 1997;15(8-9):545-554.

\section{Publish your work in this journal}

The International Journal of Nanomedicine is an international, peerreviewed journal focusing on the application of nanotechnology in diagnostics, therapeutics, and drug delivery systems throughout the biomedical field. This journal is indexed on PubMed Central, MedLine, CAS, SciSearch ${ }^{\circledR}$, Current Contents ${ }^{\circledR} /$ Clinical Medicine,
Journal Citation Reports/Science Edition, EMBase, Scopus and the Elsevier Bibliographic databases. The manuscript management system is completely online and includes a very quick and fair peer-review system, which is all easy to use. Visit http://www.dovepress.com/ testimonials.php to read real quotes from published authors. 